\title{
In Defense of Realism and Selectivism from Lyons's Objections
}

\author{
Seungbae Park \\ Ulsan National Institute of Science and Technology \\ The Republic of Korea
}

Published in Foundations of Science

Citation Info: https://doi.org/10.1007/s10699-019-09614-7

pdf:

https://link.springer.com/epdf/10.1007/s10699-019-09614-

7?author_access token=GR1iv5ifxXDxVCYPV-

F0Dfe4RwlQNchNByi7wbcMAY5OUAHdOKBAk3Ehy2LNVqAFd1fr7D77KDnKde_Crga

CRwR87TwXg31QeUMp3d-0WY-WhJY1lta2e7TbszUQvsLKVAEwldJ-G_k-

HIV9ZZ82rg\%3D\%3D

\begin{abstract}
Lyons (2016, 2017, 2018) formulates Laudan's (1981) historical objection to scientific realism as a modus tollens. I present a better formulation of Laudan's objection, and then argue that Lyons's formulation is supererogatory. Lyons rejects scientific realism (Putnam, 1975 ) on the grounds that some successful past theories were (completely) false. I reply that scientific realism is not the categorical hypothesis that all successful scientific theories are (approximately) true, but rather the statistical hypothesis that most successful scientific theories are (approximately) true. Lyons rejects selectivism (Kitcher, 1993; Psillos, 1999) on the grounds that some working assumptions were (completely) false in the history of science. I reply that selectivists would say not that all working assumptions are (approximately) true, but rather that most working assumptions are (approximately) true.
\end{abstract}

\section{Keywords}

Counterexample Formulation, Modus Tollens Formulation, No-Miracles Argument, Scientific Realism, Selectivism

\section{Introduction}

What exactly does Hilary Putnam's (1975) scientific realism say? Is it justifiable for Timothy Lyons $(2016,2017,2018)$ to construe Larry Laudan's (1981) historical objection to scientific realism as a modus tollens? What counts as a miracle in Putnam's (1975) no-miracles argument (NMA)? Is the selectivist explanation (Kitcher, 1993; Psillos, 1999) of the success of theories tenable? Lyons, who has been a leading participant in the realism debate since the turn of the twenty-first century, defends his answers to these questions. His answers sound so convincing that once you are exposed to them, you would be tempted to think that realism and selectivism are beyond salvage. This paper, however, criticizes his answers and defends opposing answers.

In Section 2, I present textual evidence concerning the NMA to show that realism is not the categorical hypothesis that all successful theories in science are (approximately) true, but rather the statistical hypothesis that "most successful theories are (approximately) true" (Parka, 2018: 55). In Section 3, I present textual evidence concerning Laudan's (1981) objection to realism with the intent of showing that he has not constructed the pessimistic induction, and that he has merely presented some historical counterexamples to refute the 
categorical hypothesis. I also argue that it is otiose for Lyons to formulate Laudan's objection as a modus tollens. In Section 4, I argue that what counts as a miracle in the NMA is not that one successful theory in science is (completely) false, but rather that most successful theories in science are (completely) false. In Section 5, I argue that selectivists would assert not that all working assumptions are (approximately) true, but rather that most working assumptions are (approximately) true. In Section 6, I respond to reviewers' comments.

In the end, all these sections are intended to show that realism and selectivism are immune to Lyons's objections. So this paper would be useful especially to those who are interested in what exactly realism and selectivism assert, and what objections would refute them.

This paper does not attempt to refute Lyons's $(2003,2017,2018)$ variant of surrealism (surrogate for realism). He has put it forward as an alternative to realism and selectivism. I only bring the reader's attention to the facts that Park (2014) has constructed the pessimistic induction against Lyons's form of surrealism, that Park (2016) has exposed intrinsic problems with surrealism in general, and Park (forthcoming: Section 5) has exposed intrinsic problems with Lyons' version of surrealism in particular.

\section{The No-Miracles Argument}

Science is a successful enterprise in that it can explain and predict many phenomena. Putnam (1975: 73) considers two rivaling hypotheses explaining the success of theories in science. The first hypothesis holds that successful theories are mostly (approximately) true, and that no miracle has occurred. The second hypothesis holds that successful theories are mostly (completely) false, and that a miracle has occurred. A miracle is not a satisfactory explanans. Therefore, the first hypothesis best explains why science is successful. This is the famous NMA. Putnam puts it as follows:

The positive argument for realism is that it is the only philosophy that doesn't make the success of science a miracle. That terms in mature scientific theories typically refer (this formulation is due to Richard Boyd), that the theories accepted in a mature science are typically approximately true, that the same term can refer to the same thing even when it occurs in different theories these statements are viewed by the scientific realist not as necessary truths but as part of the only scientific explanation of the success of science, and hence as part of any adequate scientific description of science and its relations to its objects. (Putnam, 1975: 73)

What does realism say in the NMA? It says not that successful theories are guaranteed to be (approximately) true, but rather that they are typically (approximately) true. In other words, realism is not the categorical hypothesis but rather the statistical hypothesis (Magnus and Callender, 2014: 323; Mizrahi, 2013: 3224; Park, 2017a: 71). Thus, realism is not refuted even if some successful theories are (completely) false. Even if realism is the statistical hypothesis, it is a scientific hypothesis, and it can explain why some theories in science are successful. After all, as Carl Hempel (1966: 58-59) notes, many scientific hypotheses are statistical, and yet they can explain phenomena.

What counts as a miracle in the NMA? The NMA says not that the success of a scientific theory would be a miracle if it were (radically) false, but rather that the success of theories in science would be a miracle if most of them were (radically) false. Thus, what counts as a miracle in the NMA is not that a (completely) false theory is successful, but rather that most successful theories are (completely) false. To put it differently, a miracle has occurred if and only if realism is false.

In the following sections, readers will see that the NMA, construed in the manner stated above, is immune to both Laudan's objection and Lyons's objection, that Lyons has 
misconstrued the NMA, and that his version of the NMA is stronger than Putnam's version of the NMA.

\section{Laudan's Objection}

Laudan's (1981) objection to realism is simple and clear. It says that there are many historical counterexamples to the aforementioned categorical hypothesis. Laudan (1981: 33) presents his infamous list of obsolete theories, and then contends that "there is no necessary connection between increasing the accuracy of our deep-structural characterizations of nature and improvements at the level of phenomenological explanations, predictions and manipulations" (1981: 35). He concludes his paper by saying that realists' "epistemology is confronted by anomalies which seem beyond its resources to grapple with" (Laudan, 1981: 47-48).

Two things about Laudan's objection are noteworthy. First, it takes realism as asserting not that success and truth are reliably connected with each other, but rather that they are necessarily connected with each other. In other words, it takes realism to be not the statistical hypothesis but rather the categorical hypothesis. Second, his purpose of providing the infamous list is not to construct the pessimistic induction but rather to confute the categorical hypothesis. To use an analogy, he presents some black swans to refute the categorical statement that all swans are white.

Laudan's objection differs significantly from the pessimistic induction. The latter claims that "we are in the midst of an ongoing historical process in which our theoretical conceptions of nature will continue to change just as profoundly and fundamentally as they have in the past" (Stanford, 2015: 875). Note that it predicts that present theories will be abandoned. By contrast, Laudan's objection is silent about whether they will be abandoned. Many writers, however, do not distinguish between Laudan's objection and the pessimistic induction, attributing the pessimistic induction to Laudan (1981). They are Philip Kitcher (1993: 149), Jarrett Leplin (1997: 137), Markus Eronon (2017), Peter Vickers (2017: 3221), and Jeffrey Seeman (2018: 3). To reiterate, the pessimistic induction cannot be found in Laudan (1981). ${ }^{1}$

Why is it important to distinguish between Laudan's objection and the pessimistic induction? Laudan's objection is compatible with the statistical hypothesis, while the pessimistic induction is not. Laudan's objection says that some successful theories are (radically) false, whereas the pessimistic induction says that most successful theories are (radically) false. Obviously, the latter clashes with the statistical hypothesis, whereas the former does not. To use an analogy, the statement that most swans are black conflicts with the statement that most swans are white, whereas the statement that some swans are black does not. Thus, if antirealists wish to reject realism, they should not settle for Laudan's objection, but they should rather go for the pessimistic induction.

I argued above that Laudan presents some historical counterexamples to refute the categorical hypothesis. Let me call this formulation of Laudan's objection the counterexample formulation. Lyons, however, presents a different formulation of Laudan's objection. He claims that Laudan's objection can be properly formulated as the following modus tollens:

\footnotetext{
${ }^{1}$ It can be found elsewhere, where Laudan says, "Most of the past theories of science are already suspected of being false; there is presumably every reason to anticipate that current theories of science will suffer a similar fate" (1977: 126).
} 
1. If (a) that realist meta-hypothesis were true, then (b) we would have no successful theories that cannot be approximately true. (If we did, each would be a "miracle," which no one of us accepts.)

2. However, (not-b) we do have successful theories that cannot be approximately true: the list (of "miracles").

3. Therefore, (not-a) the realist meta-hypothesis is false. (And the no-miracles argument put forward to justify that meta-hypothesis is unacceptable.) (Lyons, 2016: 566)

To put it simply, if realism were true, no successful theory is (completely) false. But some successful theories were (completely) false. Therefore, realism is false. ${ }^{2}$ Lyons (2003: 898, 2016: 566, 2017: 7, 2018: 146) continues to present this formulation of Laudan's objection in the literature. Let me call it the modus tollens formulation. The modus tollens formulation and the counterexample formulation mentioned above are different formulations of the same objection to realism, viz., Laudan's objection.

What are we to make of the modus tollens formulation? Admittedly, it captures Laudan's objection. Such a formulation, however, is supererogatory. Laudan has presented not the modus tollens formulation but rather the counterexample formulation as we have seen above. More importantly, the counterexample formulation is shorter, simpler, and clearer than the modus tollens formulation. We should not complicate an idea beyond necessity, i.e., without a theoretical gain. Suppose that one presents some black swans to refute the categorical statement that all swans are white. Of course, this objection can be reconstructed as the following modus tollens. If all swans are white, there would be no black swans. But there are some black swans. Therefore, it is false that all swans are white. Such a reconstruction, however, is gratuitous because it is longer, more complicated, and less clear than the formulation that there are some counterexamples, viz., some black swans, to the categorical statement that all swans are white. There is no need to complicate the objection by reconstructing it as the modus tollens. Similarly, there is no need for Lyons to complicate Laudan's objection by reconstructing it as the modus tollens.

Lyons might retort that the modus tollens formulation has a theoretical advantage over the pessimistic induction. The advantage is that the former gets around many realist objections to the latter. For example, many realists object that present theories are superior to their predecessors, so the former might not be abandoned, although the latter were abandoned (Musgrave, 1985; Leplin, 1997; Doppelt, 2007, 2011, 2014; Saatsi, 2009; Fahrbach, 2011a, 2011b; Devitt, 2011; Park, 2011; Mizrahi, 2013). This criticism against the pessimistic induction does not apply to the modus tollens formulation. After all, even if presently accepted theories have empirically improved upon their forerunners, their forerunners are still counterexamples to the categorical hypothesis.

This defense of the modus tollens formulation, however, misses the point of my objection to it. I am saying not that the modus tollens formulation has no theoretical advantage over the pessimistic induction, but rather that the modus tollens formulation has no theoretical advantage over the counterexample formulation. Lyons $(2003,2016,2017,2018)$ does not attempt to demonstrate the superiority of the modus tollens formulation over the counterexample formulation. He merely states that the modus tollens formulation is proper, and proposes that we construe Laudan's objection as a modus tollens. Admittedly, the modus tollens formulation is proper in that it captures Laudan's objection. The counterexample

\footnotetext{
2 Since Laudan's objection can be formulated as a modus tollens, it is inadequate to call it the pessimistic metainduction (Park, 2019a: Subsection 4.3)
} 
formulation, however, is also proper in that very sense.

I argued above that the counterexample formulation of Laudan's objection does not confute realism. What about the modus tollens formulation? It does not refute realism either. The first premise of the modus tollens above is false. In other words, it is false that if realism were true, no successful theory is (completely) false. As we have already noted, the statistical hypothesis allows for some successful theories to be (completely) false. Since the first premise is false, the modus tollens is not sound and does not have the force to refute realism.

\section{Miracles}

I argued above that realism is not the categorical hypothesis but rather the statistical hypothesis. Lyons, however, has anticipated this critical response to his objection to realism. He says that realists might advance what he calls the statistical meta-hypothesis that "predictively successful theories are statistically likely to be approximately true" (Lyons, 2016: 572). However, he objects that the statistical meta-hypothesis has the following two problems: "Not only would a retreat to this statistical meta-hypothesis diminish (but not eliminate) the testability of the realist meta-hypothesis; it would also wholly concede to miracles and to a failure on the part of the realist to explain successful theories" (Lyons, 2016: 572).

What are we to make of these two criticisms against the statistical hypothesis? First of all, the statistical hypothesis coincides with realism in the NMA. So even if realists embrace the statistical hypothesis over the categorical hypothesis, they have not made any retreat. They are rather sticking to their original position. Lyons thinks that endorsing the statistical hypothesis is a retreat because he has stretched realism.

How about Lyons's criticism that the statistical hypothesis is less testable than the categorical hypothesis? Admittedly, the statistical hypothesis is less refutable than the categorical hypothesis, given that some successful (completely) false theories do not refute the statistical hypothesis, though they refute the categorical hypothesis. This does not mean, however, that the statistical hypothesis is unfalsifiable. There are two ways for antirealists to falsify the statistical hypothesis. First, they might randomly select some successful theories from the set of past and present theories, and then show that most of the selected theories are (completely) false. If they accomplish this feat, realists would be happy to admit that realism is falsified. Of course, accomplishing this task is much more difficult than merely providing some successful theories from the history of science. This does not mean, however, that realism is not falsifiable. It only means that antirealists would have to work harder than Laudan and Lyons do. Second, antirealists might establish the pessimistic induction. If it is cogent, then past, present, and future theories are likely to be (completely) false, and hence realism is falsified. If, however, antirealists take this route to refute realism, they would have to overcome all the criticisms that realists have raised against the pessimistic induction over the past several decades. ${ }^{3}$

How about Lyons's criticism that the statistical hypothesis concedes to miracles? Evaluating this criticism requires that we ponder what counts as a miracle under Lyons's criticism. Lyons's criticism presupposes that if one successful theory is (completely) false, we have a miracle, and that if two successful theories are (completely) false, we have two miracles, and so on. This interpretation of the NMA, however, is incorrect. Putnam has never stated that the number of miracles is the same as the number of successful (completely) false theories. As we noted earlier, he rather states that a miracle has occurred when most

\footnotetext{
${ }^{3}$ See Park (2018b: 15$)$ for a summary of all those criticisms.
} 
successful theories in science are (completely) false. Suppose that there are one hundred successful theories in science, and that ninety of them are (completely) false. In such a case, Putnam would be happy to admit that a miracle has occurred. What if ten of them are (completely) false? In such a case, he would not say that a miracle has occurred, let alone that ten miracles occurred. Therefore, it is the straw man fallacy for Lyons to say that the statistical hypothesis concedes to miracles.

\section{Selectivism}

In this section, I introduce selectivism and Lyons's objection to it. I then argue that Lyons's objection to it fails in the way that his objection to realism fails.

Selectivism (Kitcher, 1993; Psillos, 1999) holds that we should be selective about different components of theories. Some components, which are called working assumptions, are deployed to generate the success of theories, while other components, which are called idle assumptions, are not. Working assumptions survive scientific revolutions while the idle assumptions do not. So the working assumptions are credible, while the idle assumptions are not. Different selectivists identify different theoretical constituents as working assumptions (Lyons, 2017: 13).

Selectivism is generally regarded as a form of realism in the literature. So many readers of this paper would wonder what the differences between realism (Putnam, 1975) and selectivism are. The fundamental difference between them is that realism denies, while selectivism affirms, that successful current theories will undergo scientific revolutions (Park, 2017a: 65, 2017b: 98-99, 2018a: 60-61, 2019b: 94; Stanford, 2018: 79). In other words, realism asserts that they will at most be slightly modified, whereas selectivism asserts, as pessimism does, that they will be replaced by alternatives.

Selectivists might object that it is a mistake for me to contrast realism with selectivism. As countless writers have indicated over the years, selectivism is an approach to realism, not a competitor. ${ }^{4}$

I insist, however, that selectivism is not a variant of realism. Selectivism lies somewhere between realism and pessimism. No selectivist has yet responded to Stanford's (2015) criticism that there is no substantive difference between selectivism and pessimism. What is his criticism? Selectivists claim, for example, that the oxygen theory is approximately true on the grounds that it will share working assumptions with its successor, just as the phlogiston theory shares working assumptions with the oxygen theory. By contrast, pessimists deny that the oxygen theory is approximately true on the grounds that its successor will radically and profoundly differ from it, just as the oxygen theory radically and profoundly differs from the phlogiston theory. According to Stanford, the difference between pessimism and selectivism "is simply a difference of style or taste in applying the expression 'approximately true' rather than a substantive disagreement between them" (Stanford, 2015: 875). This remark implies that it is a matter of taste to choose selectivism over pessimism or vice versa. Stanford proposes that realists and pessimists debate over whether there will be scientific revolutions or not, instead of debating over whether theories are approximately true or not. On his account, the substantive debate between realists and pessimists becomes merely terminological, if realists retreat to selectivism.

I am persuaded of Stanford's foregoing observation of the difference between selectivism and pessimism. Let me add that many writers have developed various positions in

\footnotetext{
${ }^{4}$ I thank a reviewer for this objection.
} 
the literature under the assumption that current theories will be overturned, viz., selective realism, structural realism, and minimal realism (Saatsi, 2015), to name a few. The 'realism' label is attached to these positions. They, however, are committed so little to the claims of science that they do not deserve the label. 'Selectivism,' 'structuralism,' and 'minimalism' are more accurate names than 'selective realism,' 'structural realism,' and 'minimal realism,' respectively. In my view, only the position stated in the no-miracles argument deserves the 'realism' label, and some participants in the realism debate need to defend this old-fashioned position for the sake of a substantive debate between them and pessimists.

Let me turn to Lyons's critical response to selectivism. He rejects the selectivist explanation of the success of theories by providing historical counterexamples, i.e., by providing some (completely) false working assumptions from the history of science. He formulates this objection as the following modus tollens:

1. If (a) the realist meta-hypothesis were true, then (b) none of the constituents genuinely deployed toward successes would be such that they cannot be approximately true. (If they were, on the realist's no-miracles argument, such constituents would constitute "miracles" which no one of us accepts.)

2. However, (not-b) we do find constituents genuinely deployed toward success that cannot be approximately true: the list (of "miracles").

3. Therefore, (not-a) the realist meta-hypothesis is false. (And the no-miracles argument put forward to justify that meta-hypothesis is unacceptable.) (Lyons, 2017: 7).

The second premise is a crucial one. In order to justify it, Lyons provides some historical examples of theoretical assumptions that he thinks were deployed to generate success but nonetheless were not even approximately true. For example, Newton deployed the theoretical assumption that "objects have an innate force, that there are only two point-mass objects in the universe, the sun and a planet" (Lyons, 2017: 3).

What would selectivists say in response? They might argue that it is debatable whether the assumptions that Lyons mentions are working or idle ones, or whether they are not even approximately true or not. Lyons would probably reply that the distinction between working and idle assumptions is not clear, and that it would stretch the notion of approximate truth to apply it to those assumptions. This paper does not jump into this debate between selectivists and Lyons because it is also a matter of taste whether we apply 'approximately true' to those assumptions or not, as Stanford (2015: 875) would point out. Moreover, it would be supererogatory for selectivists to jump into the debate, provided that they contend that most working assumptions are (approximately) true. This statistical hypothesis is compatible with the existence of Lyons's historical examples.

Lyons, however, anticipates this move and then says that the selectivists' statistical hypothesis competes with the opposite statistical hypothesis that working assumptions are "statistically unlikely to be approximately true" (Lyons, 2017: 10). Simply put, the opposite statistical hypothesis says that most working assumptions are (completely) false. Lyons is right on this count. Selectivists (Kitcher, 1993; Psillos, 1999) have some historical examples supporting their statistical hypothesis. Lyons (2017), however, also has some historical examples supporting his opposite statistical hypothesis. Both selectivists and Lyons need to show that their hypothesis is more likely to be true than the other. Lyons does not attempt to show that his opposite statistical hypothesis is more likely to be true than the selectivists' statistical hypothesis.

In this context, selectivists can appeal to historical optimism (Fahrbach, 2011a, 2011b; Park, 2011; Mizrahi, 2013, 2015, 2016). Historical optimism distinguishes between distant and recent past theories. To take an example, the phlogiston theory is a distant past theory, 
and the oxygen theory is a recent past theory. The oxygen theory is a recent past theory because it was accepted in the twentieth century, although it can also be classified as a present theory. According to historical optimism, the number of recent past theories is far larger than that of distant past theories. Moti Mizrahi $(2013,2016)$ randomly picks some samples from the set of past theories and argues that most past theories are recent past theories and are not abandoned yet. Thus, historical optimism supports the statistical hypothesis and undercuts Lyons's opposite statistical hypothesis.

\section{Objections and Replies}

My strategy to Laudan's (1980: 33) list of obsolete theories is different from that of Stathis Psillos (1999), Vickers (2017), and Mario Alai (2018). The differences between my strategy and their strategy need to be explicitly stated. ${ }^{5}$

Psillos, Vickers, and Alai are all selectivists. They look into the components of discarded past theories, emphasizing that their working assumptions were preserved in their successors. By contrast, I look into the ratio of discarded past theories to retained past theories, emphasizing that the ratio is low enough for realism. My strategy is incompatible with selectivists' prediction that present theories will succumb to scientific revolutions, but compatible with their historical contention that the working constituents of discarded past theories were preserved in current theories. I do not reject the latter, although I reject the former.

Objectors might say that I made a big fuss about realism not asserting that successful theories are guaranteed to be true but rather asserting that they are typically true. This is, however, a well-known fact about realism even if it is occasionally forgotten. It is encapsulated in the statement that the inference from success to (approximate) truth is not deductive but rather inductive, in Laudan's statement that the success of science "provides striking empirical confirmation for realism" (Laudan, 1981: 21), and in his other statement that realism "explains the fact that science is successful" (Laudan, 1981: 22). ${ }^{6}$

This objection fails to see that the inference from "some" to "all" as well as the inference from "some" to "most" is inductive. Thus, it might be the categorical hypothesis that is encapsulated in the statement that the inference from success to (approximate) truth is not deductive but rather inductive. In addition, the observation of some red apples confirms that all apples are red as well as that most apples are red. Thus, it might be the categorical hypothesis that is encapsulated in Laudan's statement that the success of science "provides striking empirical confirmation for realism" (Laudan, 1981: 21). Also, an empirical fact can be explained not only by a statistical hypothesis but also by a categorical hypothesis. Thus, it might be the categorical hypothesis that is encapsulated in Laudan's statement that realism "explains the fact that science is successful" (Laudan, 1981: 22). In short, the three statements are neutral as to whether realism is the statistical hypothesis or the categorical hypothesis.

\section{Conclusion}

The NMA defines realism not as the categorical hypothesis but rather as the statistical hypothesis, and states that we have a miracle not when a successful theory is (completely) false, but rather when most successful theories are (completely) false. It is otiose for Lyons to

\footnotetext{
${ }^{5}$ I thank a reviewer for this request.

${ }^{6}$ I thank two reviewers for this objection.
} 
formulate Laudan's objection to realism as a modus tollens, given that the counterexample formulation is shorter, simpler, clearer, and closer to Laudan's language than the modus tollens formulation is. Selectivists would say not that all working assumptions are (approximately) true, but rather that most working assumptions are (approximately) true. Moreover, they can appeal to historical optimism to justify their statistical hypothesis and to undermine Lyons's opposite statistical hypothesis. In sum, realism and selectivism remain unscathed vis-à-vis Lyons's objections. Let me finish this paper with two mottos: "Don't complicate an idea beyond necessity." "Don't' stretch a target."

\section{References}

Alai, Mario (2018). "How Deployment Realism Withstands Doppelt's Criticisms", Spontaneous Generations: A Journal for the History and Philosophy of Science 9 (1): 122135.

Devitt, Michael (2011). “Are Unconceived Alternatives a Problem for Scientific Realism?”, Journal for General Philosophy of Science 42 (2): 285-293.

Doppelt, Gerald (2007). "Reconstructing Scientific Realism to Rebut the Pessimistic Metainduction", Philosophy of Science 74 (1): 96-118.

(2011). "From Standard Scientific Realism and Structural Realism to Best Current Theory Realism", Journal for General Philosophy of Science 42 (2): 295-316.

(2014). "Best Theory Scientific Realism", European Journal for Philosophy of Science 4 (2): 271-291.

Eronen, Markus. (2017). "Robust Realism for the Life Sciences", Synthese. https://doi.org/10.1007/s11229-017-1542-5.

Fahrbach, Ludwig (2011a). "How the Growth of Science Ends Theory Change", Synthese 180 (2): 139-155.

$1283-1292$.

(2011b). "Theory Change and Degrees of Success", Philosophy of Science 78 (5):

Hempel, Carl (1966). Philosophy of Natural Science. Englewood Cliffs, NJ: Prentice-Hall.

Kitcher, Philip (1993). The Advancement of Science: Science without Legend, Objectivity without Illusion. New York: Oxford University Press.

Laudan, Larry (1977). Progress and Its Problems: Towards a Theory of Scientific Growth. California: University of California Press.

49.

(1981). "A Confutation of Convergent Realism", Philosophy of Science 48 (1): 19-

Leplin, Jarrett (1997). A Novel Defense of Scientific Realism. New York: Oxford University Press. 
Lyons, Timothy (2003). "Explaining the Success of a Scientific Theory", Philosophy of Science 70 (5): 891-901.

(2016). "Scientific Realism”, In Paul Humphreys (ed.), The Oxford Handbook of Philosophy of Science. New York: Oxford University Press: 564-584.

(2017). "Epistemic Selectivity, Historical Threats, and the Non-Epistemic Tenets of Scientific Realism”, Synthese 194 (9): 3203-3219.

(2018). "Four Challenges to Epistemic Scientific Realism", Spontaneous Generations: A Journal for the History and Philosophy of Science 9 (1): 146-150.

Magnus, P. D. and Craig Callender (2004). "Realist Ennui and the Base Rate Fallacy", Philosophy of Science 71 (3): 320-338.

Mizrahi, Moti (2013). “The Pessimistic Induction: A Bad Argument Gone Too Far", Synthese 190 (15): 3209-3226.

(2015). "Historical Inductions: New Cherries, Same Old Cherry-Picking", International Studies in the Philosophy of Science 29 (2): 129-148.

(2016). "The History of Science as a Graveyard of Theories: A Philosophers' Myth", International Studies in Philosophy of Science 30 (3): 263-278.

Musgrave, Alan (1985). "Realism vs. Constructive Empiricism", In Paul M. Churchland \& Clifford A. Hooker (eds.), Images of Science: Essays on Realism and Empiricism. Chicago: The University of Chicago Press.

Park, Seungbae (2011). "A Confutation of the Pessimistic Induction", Journal for General Philosophy of Science 42 (1): 75-84.

$3-21$.

(2014). “A Pessimistic Induction against Scientific Antirealism”, Organon F 21 (1):

--------- (2016). “Realism Versus Surrealism”, Foundations of Science 21 (4): 603-614.

(2017a). "On Treating Past and Present Scientific Theories Differently", Kriterion 31 (1): 63-75.

--------- (2017b). "Selective Realism vs. Individual Realism for Scientific Creativity", Creativity Studies 10 (1): 97-107.

(2018a). "Justifying the Special Theory of Relativity with Unconceived Methods", Axiomathes 28 (1): 53-62.

-------- (2018b). “The Grand Pessimistic Induction”, Review of Contemporary Philosophy 17: 7-19.

(2019a). "New Objections to the Problem of Unconceived Alternatives", Filosofia 
Unisinos 20 (2): (to be assigned).

33 (1): 89-106.

(2019b). "Optimistic Realism over Selectivism", Kriterion: Journal of Philosophy (forthcoming). "Critiques of Axiological Realism and Surrealism”, Acta Analytica.

Psillos, Stathis (1999). Scientific Realism: How Science Tracks Truth. New York: Routledge.

Putnam, Hilary (1975). Mathematics, Matter and Method: Philosophical Papers Volume I. Cambridge: Cambridge University Press.

Saatsi, Juha (2009). "Grasping at Realist Straws", Review Symposium, Metascience 18: 355362.

$0855-5$

Seeman, Jeffrey (2018). "From 'Multiple Simultaneous Independent Discoveries' to the Theory of 'Multiple Simultaneous Independent Errors': A Conduit in Science", Foundations of Chemistry. https://doi.org/10.1007/s10698-018-9304-0.

Stanford, P. Kyle (2015). "Catastrophism, Uniformitarianism, and a Scientific Realism Debate That Makes a Difference", Philosophy of Science 82 (5): 867-878.

(2018). “A Fond Farewell to 'Approximate Truth'?”, Spontaneous Generations: A Journal for the History and Philosophy of Science 9 (1): 78-91.

Vickers, Peter (2017). "Understanding the Selective Realist Defence against the PMI", Synthese 194 (9): 3221-3232. 